\title{
O Ambiente de Autoria do AdaptHA
}

\section{Graciela Cristina Bernardes Lima', gcblima@inf.ufrgs.br Renata Zanella ${ }^{1}$, renataz@inf.ufrgs.br Paulo Blauth Menezes ${ }^{1}$, blauth@inf.ufrgs.br}

${ }^{1}$ Instituto de Informática - Universidade Federal do Rio Grande do Sul (UFRGS) Caixa Postal 15.064 - 91.501-970 - Porto Alegre - RS - Brasil

\begin{abstract}
Resumo. AdaptHA é um ambiente de ensino adaptativo na Web baseado no modelo Hyper-Automaton que objetiva proporcionar ao aluno uma experiência de aprendizagem individualizada ao apresentar o material instrucional adaptado com base em seu nível de conhecimento e preferências. Este artigo objetiva apresentar o ambiente de autoria do AdaptHA, que reúne um rico conjunto de ferramentas que visa facilitar as tarefas de autoria do professor.
\end{abstract}

Palavras-chave: educação, autoria, adaptação, web.

\section{AdaptHA’s Authorship Environment}

\begin{abstract}
AdaptHA is an adaptive learning environment in the Web, based on Hyper-Automaton model, whose goal is bringing to the student an individualized learning experience by presenting the instructional material adapted based on his/her knowledge level and preferences. This paper aims at presenting AdaptHA's authorship environment, which groups a rich toolset whose goal is facilitating the teacher's authorship tasks.
\end{abstract}

Keywords: education, authorship, adaptation, web.

\section{Introdução}

A $W e b$ vem se apresentando um meio cada vez mais promissor para o desenvolvimento de sistemas de ensino. Um dos desafios é fazer uso das vantagens da Web, que torna a aprendizagem disponível em qualquer lugar e em qualquer momento, e criar para o aluno uma experiência de aprendizagem individualizada, que represente um significante melhoramento quando comparada à experiência de aprendizagem convencional de sala de aula.

Nesse contexto está sendo desenvolvido o AdaptHA (Lima et al., 2005), um ambiente adaptativo de ensino na Web baseado no modelo Hyper-Automaton (Machado et al., 1999) que objetiva proporcionar ao aluno uma experiência de aprendizagem individualizada ao apresentar o material instrucional adaptado com base em seu nível de conhecimento e preferências. Os mecanismos chave do AdaptHA, que viabilizam tal adaptação são: sua estrutura do modelo do domínio, cujas principais características são flexibilidade e riqueza de metadados; e sua estrutura do modelo do aluno, que mantém o histórico detalhado de todas as interações do aluno com o ambiente.

AdaptHA se baseia no Hyper-Automaton, cujo modelo suporta o gerenciamento e apresentação de hiperdocumentos instrucionais como cursos na Web. O HyperAutomaton utiliza o formalismo de Autômatos Finitos com Saída como um modelo 
estrutural para a organização de hiperdocumentos. Nesse modelo cada autômato define um curso e referencia um conjunto de hiperdocumentos independentes, tal que a estrutura navegacional do curso permanece separada do material instrucional.

A essência deste trabalho é promover um tipo de ensino que seja centrado no aluno. Entretanto, é indispensável levar em consideração que o professor possui um papel fundamental dentro do cenário educacional, sendo, portanto, imprescindível prover mecanismos que colaborem para a melhoria do seu trabalho, como por exemplo: ferramentas de autoria que facilitem a criação, manutenção e reutilização de cursos, material instrucional, avaliações, etc.; e ferramentas que possibilitem o acompanhamento contínuo do desempenho e progresso dos alunos.

A indisponibilidade de ferramentas que facilitam o trabalho do professor em um ambiente de ensino computadorizado, seja ele $W e b$ ou não, significa, em última instância, que a autoria de cursos irá exigir conhecimento de pessoal técnico, o que não é razoável. Evidentemente, esse aspecto gera uma barreira quase que intransponível para a utilização desse tipo de ambiente por parte do professor. Nesse sentido, o Adapt HA dispõe de um ambiente de autoria que reúne um conjunto de ferramentas que visa suprir essas necessidades. O ambiente de autoria do AdaptHA será examinado em detalhe na seção 3 e constitui o foco deste artigo.

Embora os termos professor e autor tenham significados diferentes, em algumas circunstâncias estes termos se confundem. É preciso deixar claro, que neste artigo, os termos professor e autor são considerados sinônimos e serão utilizados de forma intercambiável.

Este artigo está organizado da seguinte forma: na seção 2 apresenta-se a arquitetura do Adapt HA, bem como as camadas que a compõem; na seção 3 é examinado em detalhe o ambiente de autoria do AdaptHA, que constitui o foco deste artigo; na seção 4 encontra-se a conclusão, com os comentários finais e trabalhos futuros; na seção 5 encontram-se os agradecimentos e por fim, na seção 6 , as referências bibliográficas.

\section{Arquitetura do AdaptHA}

A arquitetura proposta para o AdaptHA é exibida na Figura 1 e se inspira no trabalho de (Marietto, 2000). Nas subseções seguintes são descritas as camadas desta arquitetura.

\subsection{Camada de Interface}

A Camada de Interface provê, de forma personalizada, o diálogo entre usuário e sistema. Cada tipo de usuário (aluno, autor e administrador) recebe uma interface adaptada com base no papel que desempenha no sistema. Um usuário pode assumir mais de um papel, por exemplo, um autor pode atuar também como administrador ou aluno. A Figura 2.a exibe a tela inicial do sistema, a 2.b a tela de cadastramento do usuário e a 2.c a tela que é apresentada ao usuário após seu login no sistema.

A fim de tornar o uso do sistema mais confortável e adaptado às necessidades do usuário, a camada de interface foi projetada para suportar mais de um idioma. Diz-se que sistemas com tal característica possuem suporte à internacionalização e à localização (Wikipedia, 2006). O idioma apresentado ao usuário depende de informações que seu navegador envia ao servidor Web ao requisitar uma URL (Uniform Resource Locator) qualquer. Com base nessas informações, o Adapt HA seleciona o 
idioma adequado. Atualmente os idiomas suportados são português e inglês, no entanto, devido a seu mecanismo de internacionalização e localização, o AdaptHA proporciona uma enorme facilidade para estender $\mathrm{o}$ suporte a outros idiomas, dispensando alterações em código-fonte. A Figura 3 explica o referido mecanismo.

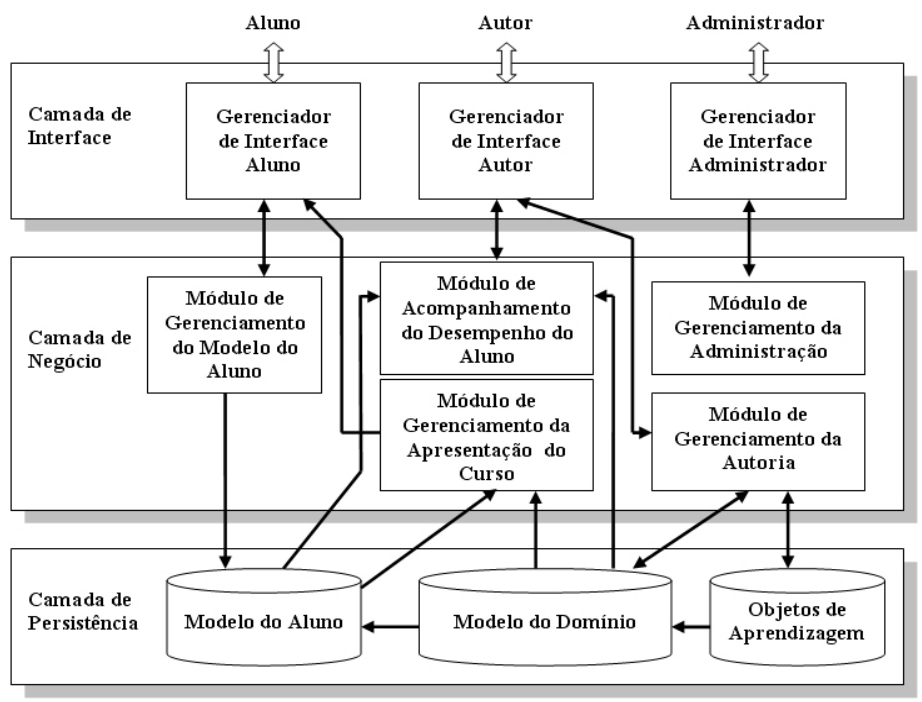

Figura 1 - Arquitetura do AdaptHA

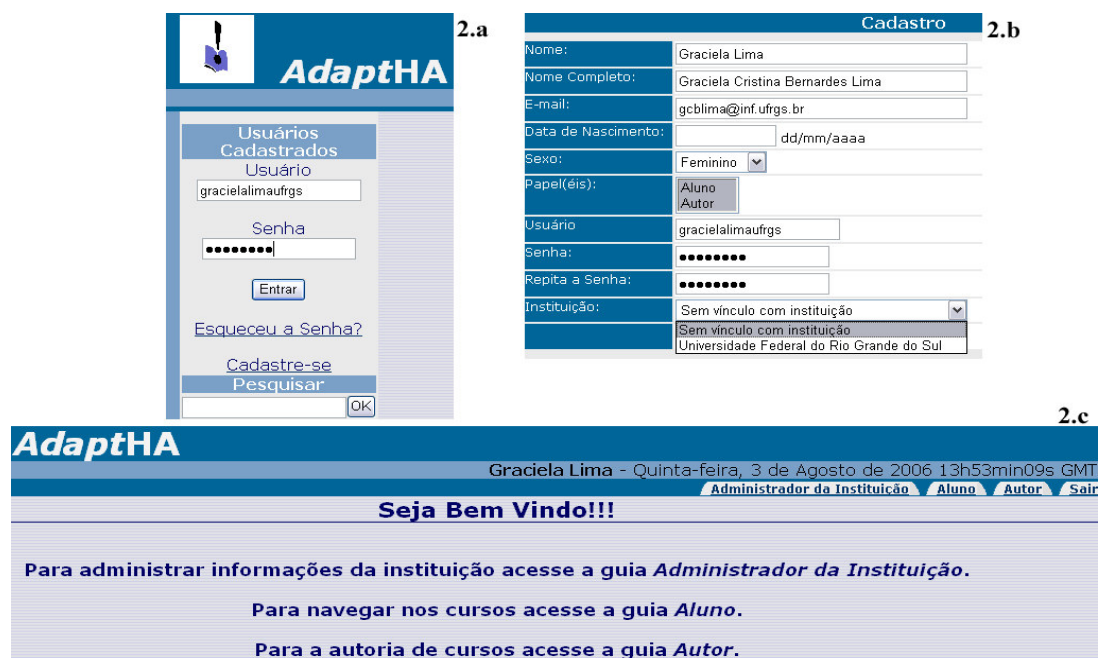

Figura 2 - A Figura 2.a exibe a tela inicial do sistema, a 2.b a tela de cadastramento do usuário e a 2.c a tela que é apresentada ao usuário após seu login no sistema.

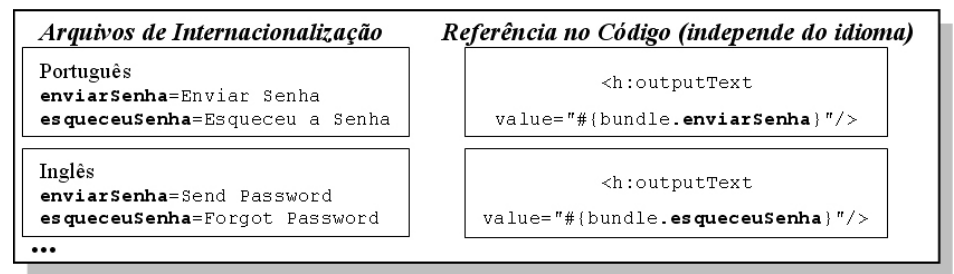

Figura 3 - Mecanismo de internacionalização e localização do AdaptHA. 


\subsection{Camada de Persistência}

De acordo com a (IEEE Computer Society, 2006), um objeto de aprendizagem é qualquer entidade, digital ou não digital, que pode ser utilizada para aprendizagem, educação ou treinamento. No AdaptHA, os objetos de aprendizagem são mantidos de maneira independente do curso, o que conseqüentemente possibilita a reutilização desses objetos em diferentes contextos.

O modelo do domínio contempla os cursos, conceitos e recursos didáticos. Entende-se como curso um conjunto de conceitos didaticamente estruturados que mantêm entre si relacionamentos de pré-requisitos. A cada conceito a ser ensinado no curso devem estar associados recursos didáticos. Recursos didáticos são conteúdos instrucionais utilizados com o objetivo de auxiliar na aprendizagem de um determinado conceito. A composição de um recurso didático pode envolver a seleção de um ou mais objetos de aprendizagem. Os recursos didáticos utilizados pelo AdaptHA são: exemplos, avaliações (diagnósticas, formativas (exercícios) e somativas) (Bloom et al., 1983), definições, dicas e textos.

Adapt HA utiliza dois tipos de modelo do aluno: estereótipo e perturbação. $\mathrm{O}$ primeiro classifica o aluno em um dos três possíveis níveis de conhecimento: básico, intermediário e avançado. Já o modelo de perturbação é utilizado para representar as concepções corretas e incorretas do aluno. O modelo do aluno contempla informações gerais (dados pessoais do aluno), informações sobre cada sessão de uso do sistema e preferências. Adapt $\mathrm{HA}$ pode se adaptar às seguintes preferências do aluno: no início de uma sessão de uso do sistema o aluno pode optar por um tipo de estratégia pedagógica ou delegar ao sistema a responsabilidade de escolher a estratégia pedagógica mais adequada (com base no modelo do aluno); presença ou não de recursos didáticos, ou seja, o aluno pode optar por receber ou não ao longo do curso, exemplos, exercícios, dicas, etc.

\subsection{Camada de Negócio}

O Módulo de Gerenciamento do Modelo do Aluno é responsável pela manutenção do modelo do aluno, podendo executar as seguintes ações: criar o modelo de um aluno; inicializar uma sessão de uso do sistema para o aluno; registrar as preferências, concepções incorretas e as alterações nos status dos conceitos do curso; registrar os erros e acertos do aluno para cada avaliação por ele realizada; e registrar cada um dos recursos didáticos do curso apresentados ao aluno.

O Módulo de Gerenciamento da Apresentação do Curso é responsável por preparar o conteúdo final que será apresentado ao aluno, com base no modelo do aluno. As etapas de preparação do conteúdo final a ser entregue ao aluno incluem: escolher uma estratégia pedagógica a ser aplicada, tomando como base as preferências e nível de conhecimento do aluno; aplicar a estratégia pedagógica selecionada no passo anterior, o que resulta em o sistema assumir comportamento diferenciado, de acordo com a estratégia pedagógica, oferecendo ao aluno menor ou maior liberdade de navegação pelo curso; e aplicar técnicas da hipermídia adaptativa (Brusilovsky, 1996) a fim de viabibilizar a adaptação de conteúdo e o suporte à navegação adaptativa.

O Módulo de Gerenciamento da Autoria é responsável pela criação e edição dos cursos, recursos didáticos e objetos de aprendizagem. Este módulo é o foco deste artigo e será detalhado na próxima seção. O Módulo de Acompanhamento do Desempenho do Aluno é responsável por disponibilizar relatórios a respeito do desempenho e progresso dos alunos em um determinado curso, tomando como base 
para isso o modelo do aluno. O Módulo de Gerenciamento da Administração possibilita que o administrador aprove o cadastro de autores e mantenha informações administrativas do sistema.

\section{O Ambiente de Autoria do AdaptHA}

Para ter acesso ao ambiente de autoria do AdaptHA, é necessário que o usuário tenha se cadastrado no sistema como autor (Figura 2.b), seu cadastro tenha sido aprovado pelo administrador e que tenha efetuado login (Figura 2.a). Feito isso, o autor deve clicar na guia Autor (Figura 2.c) e lhe será apresentada uma interface como a exibida na Figura 4.

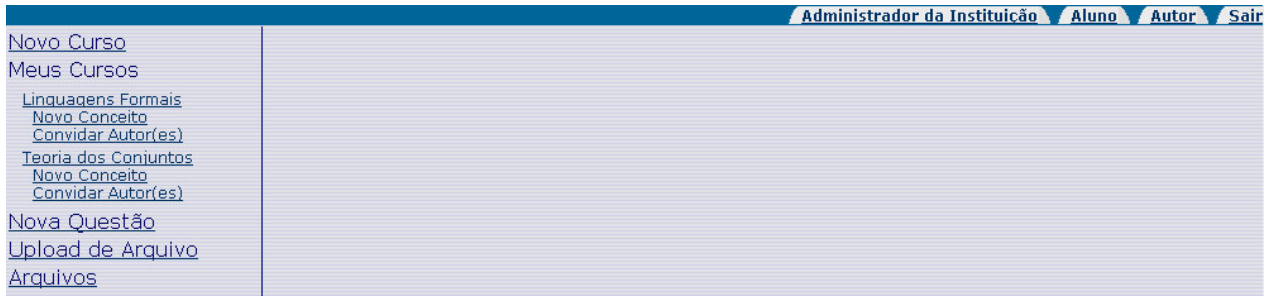

Figura 4 - Interface de autoria do AdaptHA.

\subsection{Objetos de Aprendizagem}

O upload (transferência) de objetos de aprendizagem para o servidor deve ser feito clicando-se na opção Upload de Arquivo (Figura 4), quando então é apresentada ao autor a tela mostrada na Figura 5.a. Com o objetivo de facilitar a recuperação e reutilização dos objetos de aprendizagem, são associados a cada um deles os seguintes metadados: nome; descrição; idioma; palavras-chave; autor; formato; tamanho; localização; e nível de compartilhamento, que pode ser tanto público (disponível para uso por todos os autores cadastrados no sistema) quanto privado (disponível para uso somente para o autor do objeto de aprendizagem). Vale destacar que o AdaptHA mantém os objetos de aprendizagem em local protegido no servidor, evitando dessa forma o uso indiscriminado desse material.

A visualização dos objetos de aprendizagem do autor, bem como a visualização dos objetos de aprendizagem públicos de outros autores (Figura 5.b), deve ser feita clicando-se na opção Arquivos (Figura 4). Os objetos podem ser pesquisados por seu formato (tipo de arquivo) e visualizados clicando-se no link em seu nome.

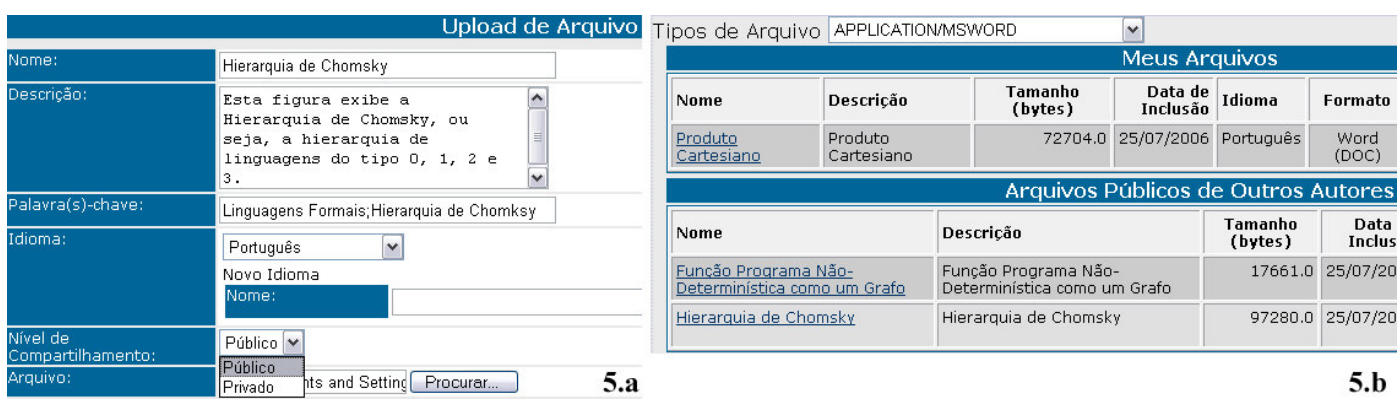

Figura 5 - A Figura 5.a exibe a interface para upload de objetos de aprendizagem e a 5.b exibe a interface para visualização de objetos de aprendizagem no AdaptHA. 


\subsection{O Editor de Textos}

Conforme mencionado anteriormente, é fundamental oferecer ao autor ferramentas que facilitem as tarefas de autoria, e nesse sentido, um ambiente como o AdaptHA deve fornecer um editor de textos que possibilite realizar operações elementares de edição de texto. Assim sendo, o AdaptHA incorporou a seu projeto o FCKeditor (FCKeditor, 2006) (Figura 6.a), um poderoso editor de textos gratuito, facilmente configurável, independente de navegador e totalmente escrito em HTML (HyperText Markup Language) e JavaScript. O fato de o FCKeditor ser escrito em HTML e JavaScript significa em última instância que para executá-lo não se faz necessária a instalação de nenhum componente no navegador do usuário.

Para inserir um objeto de aprendizagem no texto, é invocada a interface de visualização de arquivos (Figura 5.b), ligeiramente modificada (Figura 6.b) para permitir a seleção do objeto de aprendizagem desejado. Para inserir uma figura no texto, por exemplo, basta acessar a janela Formatar Figura (Figura 6.b), acionada ao se clicar no botão Inserir Figura (Figura 6.a), e em seguida clicar no botão Localizar no Servidor (Figura 6.b) para ter acesso à interface de visualização e seleção de objetos de aprendizagem.

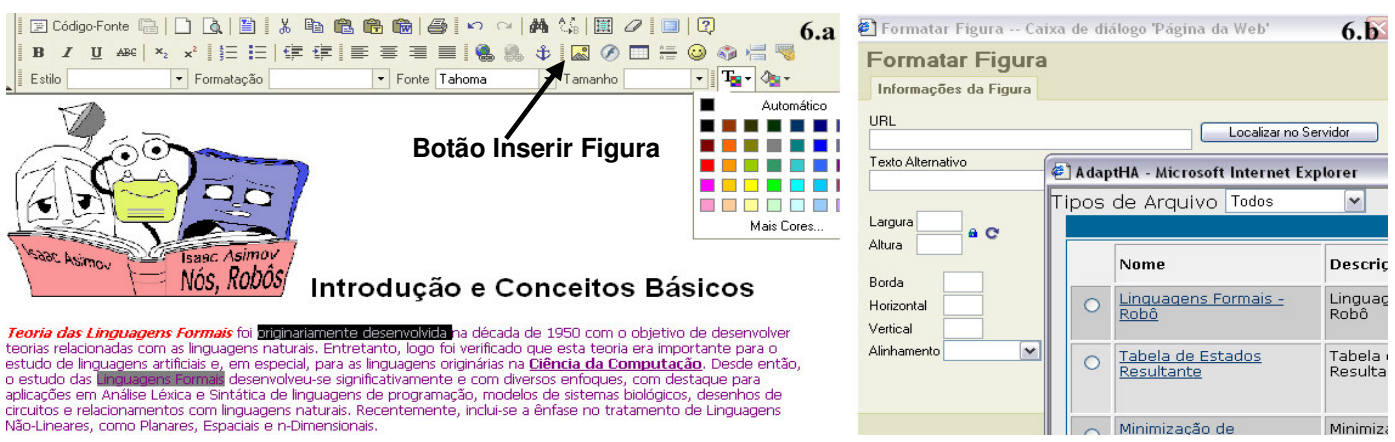

Figura 6 - A Figura 6.a exibe o FCKeditor (editor de textos do AdaptHA) e a 6.b a interface de visualização e seleção de objetos de aprendizagem.

\subsection{Questões de Avaliação}

O processo avaliativo em um ambiente de ensino é de substancial relevância. A idéia geral é utilizar os resultados das avaliações para atualizar adequadamente o modelo do aluno e então, com base nisso, oferecer feedback e orientação adequados ao aluno. Nesse aspecto, o AdaptHA dispõe de ferramentas que viabilizam a criação de questões objetivas (que podem ser de múltipla escolha ou verdadeiro/falso) e a seleção dessas questões para a elaboração de avaliações a serem aplicadas ao longo do curso. $\mathrm{O}$ ambiente para criação de questões e elaboração de avaliações do AdaptHA, se inspira fortemente no EASy (Sistema de Geração Automática de Avaliações via Web baseado no modelo Hyper-Automaton) (Zanella et al., 2005). É relevante destacar que, ao criar uma avaliação para um determinado curso, o autor tem à sua disposição um banco de questões composto por todas as questões por ele autoradas mais as questões públicas criadas por outros autores.

A Figura 7.a exibe uma visão parcial da interface de criação de questões, que pode ser acessada clicando-se na opção Nova Questão (Figura 4). Uma questão pode ter um número irrestrito de alternativas e para inclúi-las basta clicar no botão Adicionar Alternativa (Figura 7.b). Já para excluir uma alternativa é necessário clicar no botão Excluir (Figura 7.b). Ao marcar o botão de rádio (Figura 7.b) a alternativa se torna verdadeira. Quando a questão é de múltipla escolha, permite-se marcar somente uma 
das alternativas como verdadeira, quando a questão é do tipo verdadeiro/falso esta restrição não é imposta.

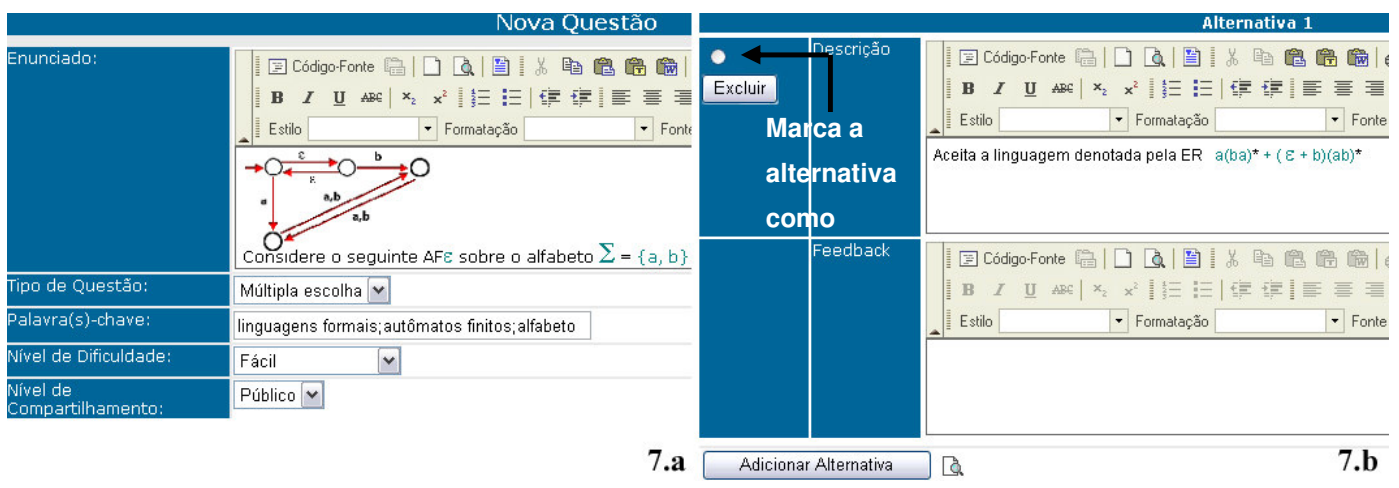

Figura 7 - A Figura 7.a exibe parte da interface de criação de questões, a 7.b exibe a mesma interface, destacando a criação de alternativas de questões no AdaptHA.

\subsection{Criando Cursos}

Para criar um curso no AdaptHA, o autor deve primeiramente clicar na opção Novo Curso (Figura 4), quando então lhe será apresentada a interface exibida na Figura 8.a. A um curso devem ser associados os seguintes metadados: nome; descrição; disciplina; áreas a que objetiva atender; nível de abrangência (o curso é abrangente ou profundo?); nível de compartilhamento, que pode ser tanto público (o curso estará disponível para quaisquer alunos cadastrados no sistema) quanto privado (o curso estará disponível somente para um grupo restrito de alunos cadastrados no sistema); idioma em que está disponível; e grau de desempenho, ou seja, um percentual de acerto nas avaliações realizadas pelo aluno, que permita classificar seu nível de conhecimento como básico, intermediário ou avançado.

A etapa seguinte de elaboração de um curso consiste em definir os conceitos que integrarão o curso e como tais conceitos se relacionam. Em essência, nesta etapa, o autor define o autômato que representa a estrutura navegacional do curso. Para criar um conceito, basta clicar no link Novo Conceito (Figura 4) do curso desejado. A Figura 8.b mostra parte da interface de criação de conceitos do Adapt HA.

A última etapa de elaboração do curso consiste em preparar o conteúdo instrucional que o conceito deve abordar. A Figura 9 mostra como o AdaptHA estrutura o conteúdo instrucional dos conceitos dos cursos. Imediatamente abaixo do conceito, encontra-se o elemento estrutural, cujo objetivo é agregar um conjunto de eventos de instrução (Gagne, 85) citado por (Marieto, 2000) (Gagne, et al., 92) citados por (Marietto, 2000) a serem aplicados com um propósito específico. Por exemplo, o elemento estrutural Visão Geral (Figura 9) agrega eventos de instrução que visam diagnosticar e contextualizar o aluno antes que a instrução propriamente dita inicie. Assim sendo, a Visão Geral inclui os seguintes eventos de instrução: diagnóstico do conhecimento do aluno com relação ao conceito e seus pré-requisitos; informação dos objetivos a serem alcançados; introdução ao conteúdo que será trabalhado posteriormente; e apresentação dos pré-requisitos do conceito.

Um dos aspectos mais importantes da etapa de entrada de conteúdo, é que nela se define o quão adaptativo o sistema será para o aluno. O AdaptHA fornece mecanismos que viabilizam a elaboração de cursos adaptativos, entretanto, cabe ao autor decidir o grau de adaptação que será oferecido ao aluno, sendo possível, inclusive, 
não ser oferecido grau algum de adaptação. Caso o autor queira elaborar um conteúdo adaptativo, é necessário pensar em duas dimensões de adaptação: áreas às quais o curso atende e nível de conhecimento do aluno. A Tabela 1 mostra o relacionamento entre os elementos estruturais, eventos de instrução e capacidade de adaptação às dimensões área e nível de conhecimento do aluno.
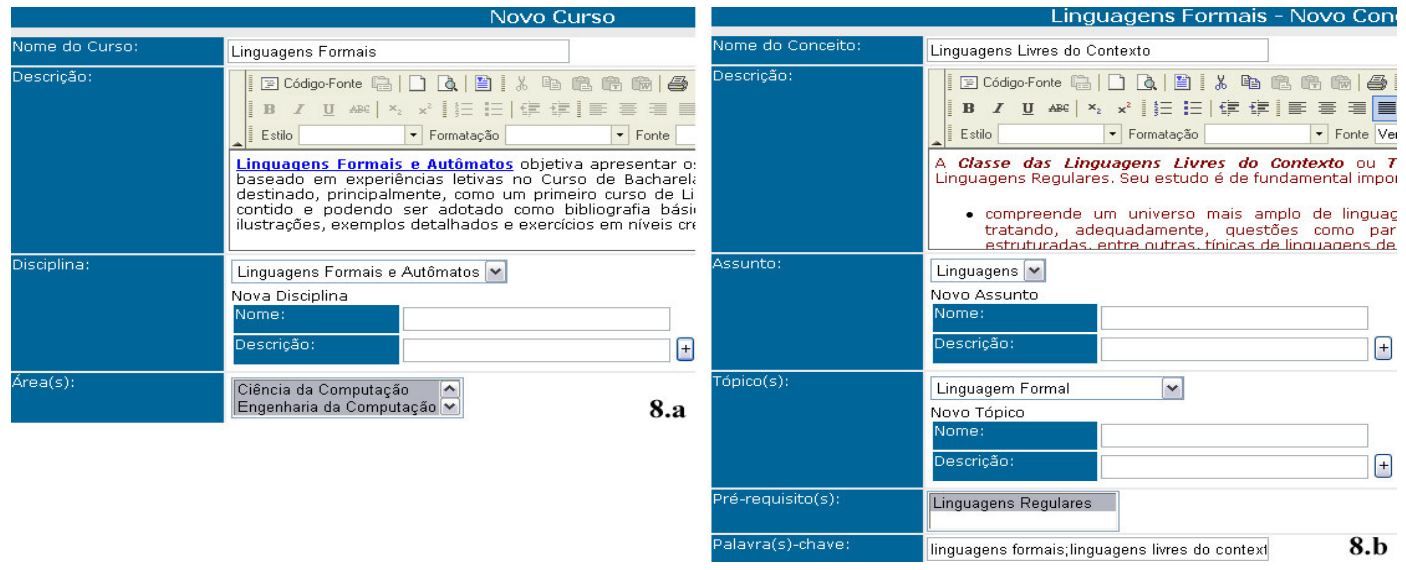

Figura 8 - A Figura 8.a exibe parte da interface de criação cursos e a 8.b parte da interface de criação de conceitos do AdaptHA.

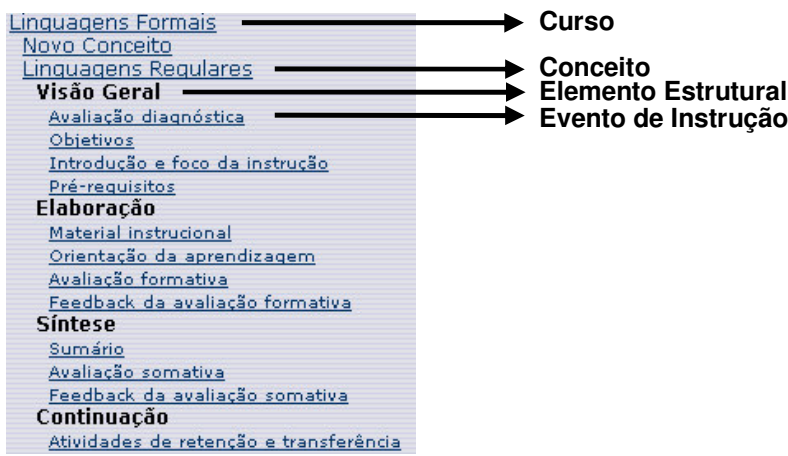

Figura 9 - Estruturação do conteúdo dos conceitos no AdaptHA.

Tabela 1 - Relaciona os elementos estruturais, eventos de instrução e capacidade de adaptação para as dimensões área e nível de conhecimento do aluno

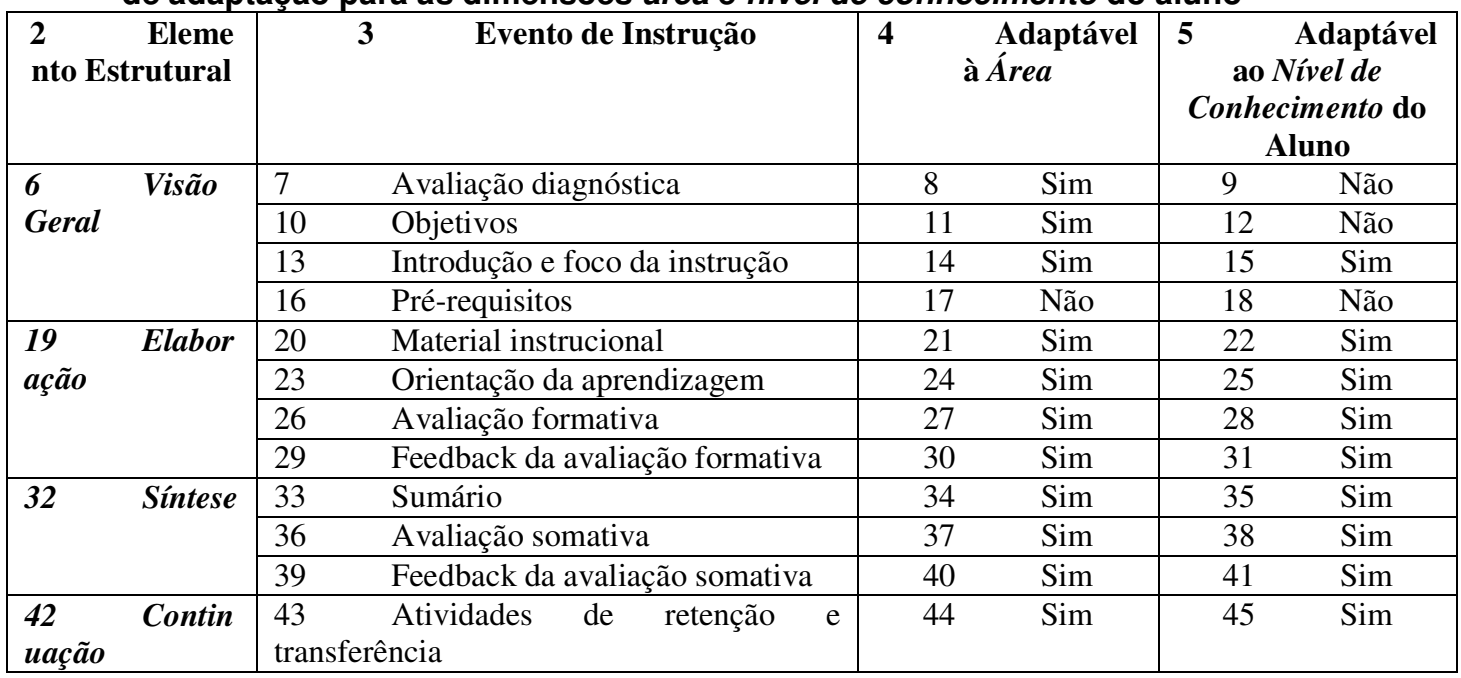

A fim de esclarecer o mecanismo que viabiliza a adaptação, tome-se como exemplo, um curso de Linguagens Formais, que visa atender às áreas de Ciência da 
Computação e Engenharia da Computação (Figura 8.a). Tendo o autor criado o conceito de Linguagens Regulares, tornar-se-ão disponíveis os elementos estruturais, com seus respectivos eventos de instrução (Figura 9). Supondo-se que o autor deseja elaborar uma avaliação diagnóstica, o evento de instrução Avaliação diagnóstica (Figura 9) deve ser clicado. Com isso, será apresentada ao autor a interface exibida na Figura 10. Com base na informação contida na Tabela 1, o AdaptHA apresenta ao autor a possibilidade de criar avaliações diagnósticas diferentes para cada área, ou criar a mesma avaliação diagnóstica para todas as áreas do curso. Supondo-se que o autor deseja elaborar um texto introdutório para focalizar a instrução, o evento de instrução Introdução e foco da instrução (Figura 9) deve ser clicado. Com isso, será apresentada ao autor a interface exibida na Figura 11. Com base na informação contida na Tabela 1, o AdaptHA apresenta ao autor a possibilidade de criar textos diferentes para cada área e para cada nível de conhecimento do aluno.

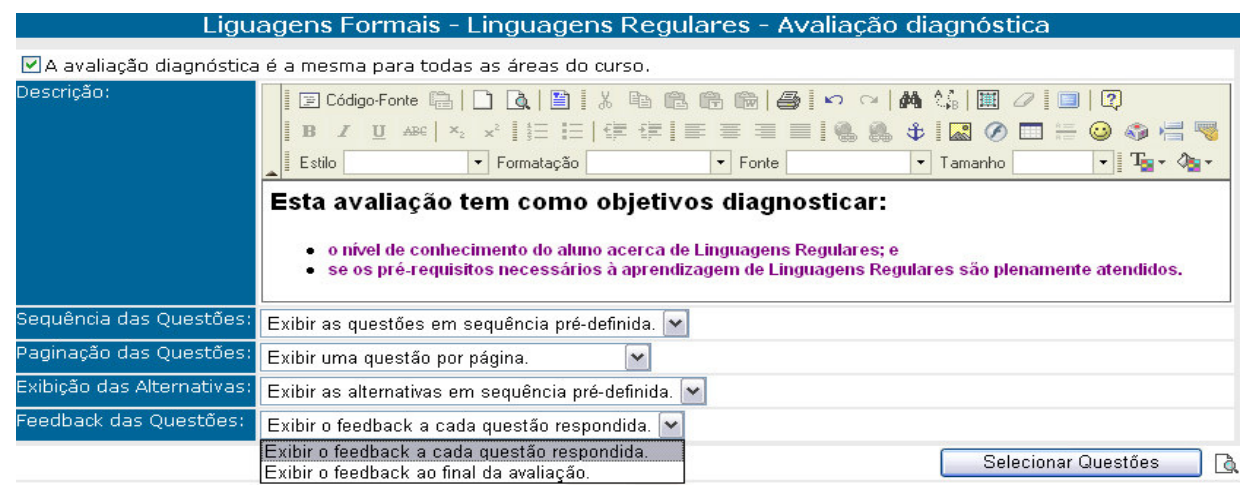

Figura 10 - Interface de criação de avaliações diagnósticas no AdaptHA.

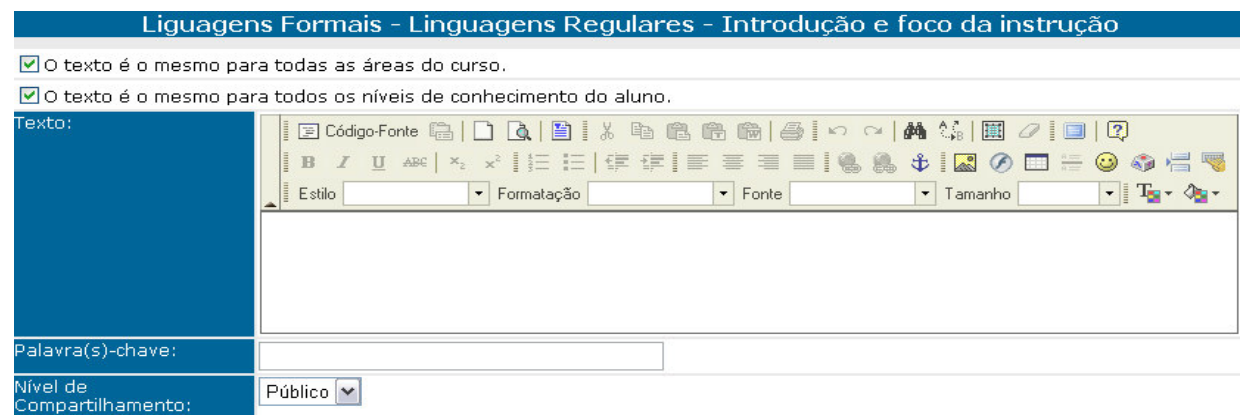

Figura 11 - Interface de criação de textos no AdaptHA.

\section{Conclusão}

Conforme mencionado anteriormente, é fundamental que sistemas de ensino computadorizados, Web ou não, forneçam ferramentas que verdadeiramente facilitem o trabalho de autoria do professor. A facilidade a ser oferecida ao professor, deve ser implementada em um ambiente de autoria pensando-se em três aspectos: facilidade para criar conteúdo instrucional; facilidade para recuperar eficientemente conteúdo instrucional; e facilidade para reutilizar conteúdo instrucional.

Considerando-se o ambiente de autoria do AdaptHA, apresentado neste artigo, é possível constatar que os aspectos de facilidade, mencionados acima, foram implementados neste ambiente, pois: a criação de conteúdo instrucional é enormemente facilitada devido ao editor de textos (FCKeditor) embutido no ambiente; a recuperação de conteúdo instrucional é facilitada devido à riqueza de metadados associados aos conteúdos autorados; e a reutilização é facilitada porque os conteúdos autorados são 
mantidos de maneira independente do curso, sendo apenas referenciados pelos que os utilizam.

O trabalho desenvolvido até então, abre um leque de oportunidades que podem ser exploradas em trabalhos futuros, como por exemplo: com a finalidade de facilitar ainda mais a criação de cursos, desenvolver um módulo de importação de cursos que permita transformar automaticamente arquivos de texto, de diversos formatos, em cursos do AdaptHA; criar um mecanismo que permita exportar cursos em formatos de texto, de maneira que o aluno possa ter acesso aos cursos, mesmo estando offline; desenvolver um applet com interface gráfica sofisticada o suficiente que permita ao professor criar, editar e visualizar os conceitos do curso e seus relacionamentos, poupando-lhe desta forma bastante trabalho.

\section{Agradecimentos}

Este trabalho está sendo parcialmente financiado pelo CNPq (Projetos HoVer-CAM, GRAPHIT, E-Automaton) e FINEP/CNPq (Projeto Hyper-Seed).

\section{Referências Bibliográficas}

Bloom, B. S.; Hastings, J. T.; Madans, G. F. Manual de Avaliação Formativa e Somativa da Aprendizagem Escolar. São Paulo: Pioneira. 1983. 307 p.

Brusilovsky, P. Methods and Techniques of Adaptive Hypermedia. In: User Modeling and User Adapted Interaction, 1996.

FCKeditor. FCKeditor, the text editor for Internet. Disponível em $<$ http://www.fckeditor.net/>. Acesso em 10 ag. 2006.

IEEE Computer Society. IEEE P1484.12.3, Draft 8 Draft Standard for Learning Technology - Extensible Markup Language (XML) Schema Definition Language Binding for Learning Object Metadata. Disponível em $<\mathrm{http}: / /$ ltsc.ieee.org/wg12/files/ IEEE_1484_12_03_d8_submitted.pdf>. Acesso em 03 ag. 2006.

Lima, G. C. B.; Zanella, R.; Menezes, P. B. AdaptHA: Ambiente de Ensino Adaptativo na Web Baseado no Modelo Hyper-Automaton. In: XVI Simpósio Brasileiro de Informática na Educação, 2005, Juiz de Fora.

Machado, J. P.; Penczek, L.; Morais, C. T. Q.; Menezes, P. B. Autômatos Finitos: um Formalismo para Cursos na Web. In: XIII Simpósio Brasileiro de Engenharia de Software, p. 213-223, 1999, Florianópolis.

Marietto, M. G. B. Definição Dinâmica de Estratégias Instrucionais em Sistemas de Tutoria Inteligentes: Uma Abordagem Multiagentes na WWW, no estado de São Paulo. São José dos Campos: Instituto Tecnológico de Aeronáutica, 2000. Tese de doutorado.

Wikipedia. Internationalization and localization. Disponível em $<$ http://en.wikipedia.org/wiki/Internationalization_and_localization>. Acesso em 03 ag. 2006.

Zanella, R.; Lima G. C. B.; Antunes, B.; Menezes, P. B. EASy - Recuperação de Questões através de Metadados e Geração Automática de Instrumentos de Avaliação via Web. Renote, Porto Alegre, nov. 2005. Disponível em <http://www.cinted.ufrgs.br/renote/nov2005/index.html>. Acesso em 05 ag. 2006. 